This item was submitted to Loughborough's Research Repository by the author.

Items in Figshare are protected by copyright, with all rights reserved, unless otherwise indicated.

\title{
Economic scoring formulae in multi-Attribute construction auctions
}

PLEASE CITE THE PUBLISHED VERSION

http://doi.org/10.14455/ISEC.res.2017.73

\section{PUBLISHER}

(C) ISEC Press

\section{VERSION}

VoR (Version of Record)

\section{PUBLISHER STATEMENT}

This work is made available according to the conditions of the Creative Commons Attribution-NonCommercialNoDerivatives 4.0 International (CC BY-NC-ND 4.0) licence. Full details of this licence are available at: https://creativecommons.org/licenses/by-nc-nd/4.0/

\section{LICENCE}

CC BY-NC-ND 4.0

\section{REPOSITORY RECORD}

Ballesteros-Perez, Pablo, Eugenio Pellicer, and M. Carmen Gonzalez-Cruz. 2019. "Economic Scoring Formulae in Multi-attribute Construction Auctions". figshare. https://hdl.handle.net/2134/32782. 


\title{
ECONOMIC SCORING FORMULAE IN MULTI-ATTRIBUTE CONSTRUCTION AUCTIONS
}

\author{
PABLO BALLESTEROS-PEREZ ${ }^{1}$, EUGENIO PELLICER ${ }^{2}$, \\ and $\mathrm{M}^{\mathrm{a}}$ CARMEN GONZALEZ-CRUZ ${ }^{2}$ \\ ${ }^{1}$ School of Construction Engineering and Management, University of Reading, Reading, UK \\ ${ }^{2}$ Universitat Politècnica de València, Valencia, Spain
}

\begin{abstract}
Public tendering implies the free concurrence and competition of bidding companies that certify their solvency, so that those companies proposing the most attractive bid, both technically and economically, are awarded the contracts and carry them out according to the same terms and conditions that they proposed. Generally, there is high competition in public tendering, both concerning the number of bidders (constantly increasing), as well as the profit margin (constantly decreasing). On the other side, handling the procurement process, there is a contracting authority that spends public money while trying to fulfill a particular socio-economic objective. This paper will take the contracting authority's (auctioneer's) point of view which is in charge of devising and implementing the awarding criteria, as well as choosing the best bidder. Particularly, this paper will focus on some aspects of the Economic Scoring Formula (ESF) design. The ESF constitutes a set of mathematical expressions that transform the economic bids submitted by the bidders into scores, so that, eventually, the bidders can be ranked and the best one selected. We will conclude that, despite apparently simple, how ESF are configured eventually have profound consequences on bidding behavior and some bidding results, like a higher or lower bid dispersion.
\end{abstract}

Keywords: Bidding, Tendering, Competition, Economic bid, Bidder, Procurement.

\section{BACKGROUND}

In the European Union, the principal law for Public Procurement is the Directive 2004/18/EC, also called the Public Procurement Directive. According to this Directive, any public contract should be awarded as a function of objective criteria which assure the compliance of principles of transparency, non-discrimination, and equal treatment, and simultaneously guarantee the contracts are evaluated on conditions of effective competition (Constantino et al. 2010). The result is two basic awarding criteria mechanisms: the Lowest Price (LP), and the Most Economically Advantageous Tender (MEAT).

Generally, LP is used when the goal is to maximize savings, given that the solution is highly defined, while MEAT criteria are appropriate for complex projects whose contract objectives are variable. In the MEAT awarding mechanism, it is common to find sub criteria of valuation such as: Project duration and delivery time, operational cost, cost effectiveness, quality, aesthetics, characteristics and functions of environmental fashion, technical or innovative merit, post-sales service, guarantee period extensions, technical assistance, etc. (Pastor et al. 2010).

In Operational Research contexts, those tenders that include different awarding criteria are denominated 'multi-attribute (reverse) auctions'. However, this type of auctions exactly 
coincides with what the Directive 2004/18/EC names Most Economically Advantageous Tender (MEAT) (Perng et al. 2006; Bergman and Lundberg 2013), also known as 'Best Value Construction Auctions' (Molenaar and Johnson 2003, El Wardani et al. 2006) in the US.

The leap and conceptual differences between mono-attribute (Lowest Price) auctions and multi-attribute auctions is, however, quite significant, as accepts that the awardee can be a bidder whose bid is not necessarily the lowest increases the expectations of the companies that develop products with high quality/price relations (best value) (Ballesteros-Pérez et al. 2010).

Currently, there is a vast scientific literature regarding the creation of decision making frameworks that identify potential bidders and contractors as more or less acceptable (Bergman and Lundberg 2013). In this sense, multiple studies have focused on generating the most opportune hierarchies possible, in order to 'objectively' classify the bidders proposals (e.g. Hong 2004, Abudayyeh et al. 2007, Tsai et al. 2007), although much remains to be done in this area, the mathematical configuration of the Economic Scoring Formula is generally neglected.

Likewise, many studies have analyzed the economic behavior of bidders in reverse auctions (in auction theory and game theory, for instance), but not in multi-attribute auctions. In this sense, the mono-attribute reverse auctions constitute a simplification of a competition because contracts are awarded based on a single purely economic criterion: the lowest bid (Skitmore 2002). In multi-attribute auctions we need to provide the bidders with scores so that we can, not just 'rank/order' them, but also scored them. And 'scores' are needed otherwise there is no way to add up different criteria to decide who is the best bidder.

Therefore, the difference between auctions and multi-attribute auctions is not simply that a tender involves the weighing of non-economic criteria: economic criteria themselves are also transformed, and must be homogenously measured against other evaluation criteria (Abudayyeh et al. 2007). Of particular interest here, is the Economic Scoring Formula, which is in charge of transforming into scores the economic bids submitted by the bidders in a multi-attribute auction.

\section{ECONOMIC SCORING FORMULA (ESF)}

The conversion of price, technical and quality factors into an overall score is absolutely dependent on these two factors (Abudayyeh et al. 2007, Drew et al. 2002):

- The weights we put in each of those items or categories (mostly economic and technical)

- The mathematical formulae used for transforming into scores each proposal item (ditto).

In fact, one of the significant reasons why multiple criteria decision methods have been applied in bidding is that subsequent sensitivity analysis show that in many cases, the final order of the proposals is highly permutable according to small changes in the mathematical criteria and/or the weighting factors (Abudayyeh et al. 2007, Tsai et al. 2007).

The Economic Scoring Formula (ESF) is defined by Ballesteros-Perez (2015b) as the set of mathematical expressions that allows for a numerical score to be assigned to each bidder based on their financial proposal, including a cut-off limit (Abnormally Low Bids Criterion, ALBC) below which a bid is disqualified for being too low (Ballesteros-Pérez et al. 2015c). Recently, Ballesteros-Perez et al. (2015b, 2016) studied how different configuration aspects of the ESF affect bidders' behavior. The major outcomes from that piece of research highlight that the following configurations of ESF promote higher bidding aggressiveness and bid dispersion:

- Higher weight of the economic criterion $\left(W_{e}\right)$ vs the weight of the technical proposal $\left(W_{t}\right)$

- A lenient or even inexistent ALBC (very small number of bidders or even none are ruled out for being too cheap) 
- Concave-shaped ESF vs linear or Convex-shaped ESF (bidders scores decrease faster than with a linear gradient when they gain distance from the lowest bid)

These aspects are of great interest when a contracting authority designs an ESF, since how these scoring criteria are set will directly affect the bidders' strategy and the bids submitted.

\section{SCORING PARAMETERS (SP)}

In order to apply an Economic Scoring Formula or an Abnormally Low Bids Criterion, it is necessary to express these in terms of one or several variables. These variables are called 'Scoring Parameters (SP)', which are, at the same time, a series of parameters describing the economic bidding results (Ballesteros-Pérez et al. 2015a).

The most common SP is the lowest bid $\left(b_{\min }\right)$. In fact, in most public procurement laws, including Directive 2004/18/EC, it is obligatory that the lowest bid also has the best score, otherwise the essence in the selection of the Most Economically Advantageous Tender is lost. However, there are many possible combinations of SPs under a ESF, Figure 1 shows some of them. Particularly, in Figure 1 it is easy to find that to create an ESF (or a ALBC) one SP can be chosen (Cases 1 and 5), various SPs can be chosen (Cases 2,3,4,6), or even none chosen (case 7).

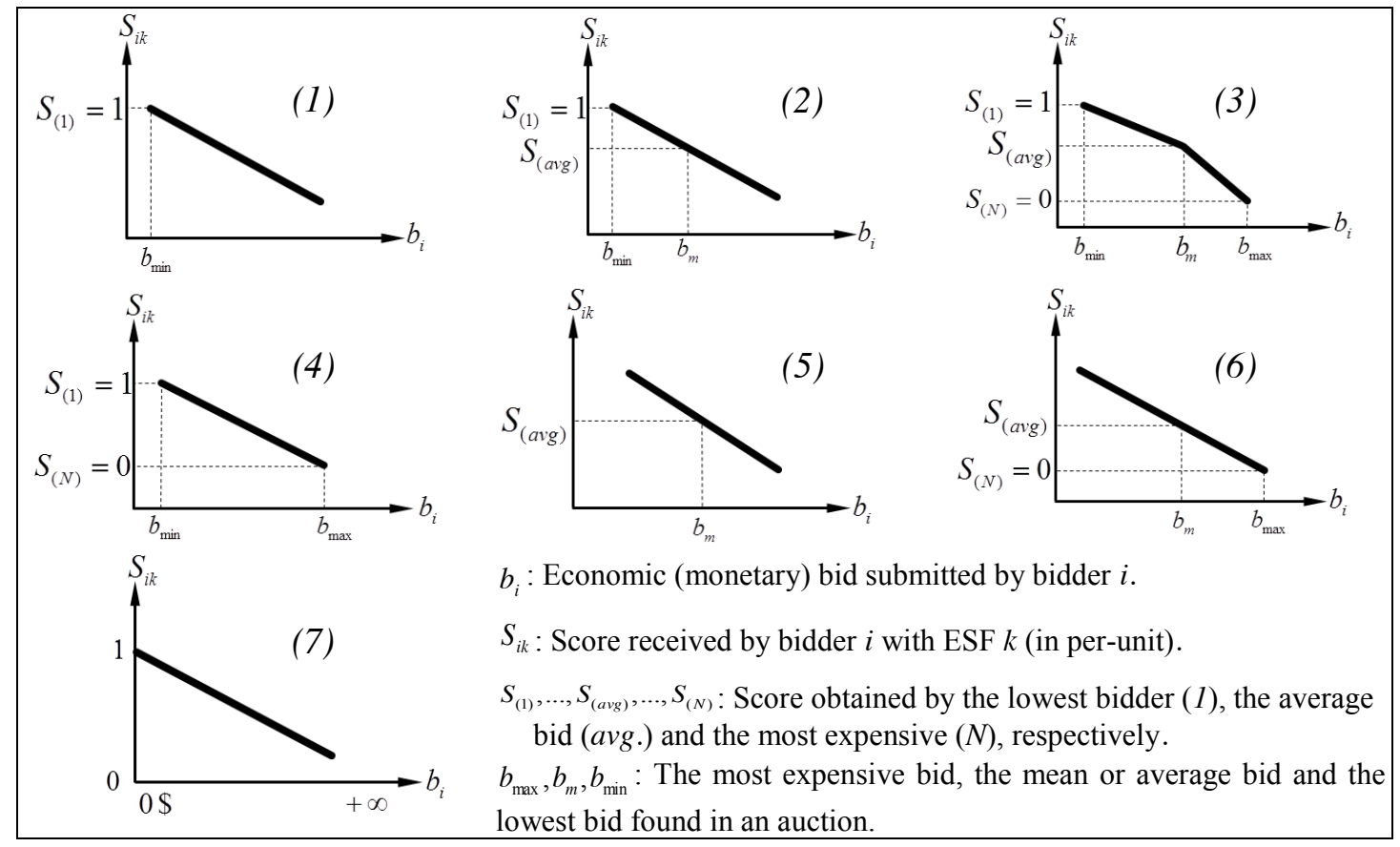

Figure 1. Possible combinations of SP in ESF.

However, ESFs do not have to implement only linear criteria. Contracting authorities have freedom to generate the mathematical expressions that they consider appropriate to score the bids (higher-order polynomials instead of straight lines or even composite functions like cases 2, 3 and 6 from Figure 1). Unfortunately, it is very common that contracting authorities do not reflect on the consequences that a particular ESF generates on the bidders' behavior. This is determined not only by the form of the employed curves, but also by the SPs used in them. 


\section{ESF WITH NO SP}

On some occasions, an ESF can be mathematically expressed only as a function of the bidders' bids $b_{i}$. The use of no SP makes the score of each bidder totally independent from the bids submitted by its competitors, which also means that the exact score that each bid will obtain is known beforehand (before the proposals submission). An example of these ESF would be Eq. (1):

$$
S_{i}=\frac{b_{i}-b}{a-b} \quad 1 \geq S_{i} \geq 0 \quad b_{i} \subset[a, b]
$$

Where $S_{i}$ is the economic score obtained by bidder $i$ who submitted a bid $b_{i}, a$ is the lower bid limit below which a bidder will not increase its score anymore, whereas $b$ is the upper bid limit above which a bidder will always get a score of zero. As can be deduced, the auctioneer or contracting authority needs to decide which will be the $a$ and $b$ values for each auction, as each construction work has a different economic size.

These ESFs, however, are not very common. The advantage of these ESF is that all bidders know from the outset the score that it will be obtained as a function of their bid. Also, the score each bidder gets is not variable depending of what the rest of the bidders do.

Concerning disadvantages: these ESF with no SP tend to promote an accumulation of bids close to the position of $a$, since all bidders feel compelled to take higher risks and lower their bids (even to unrealistic limits) when they know exactly how much score they will get in return. A second big disadvantage is that these ESF are the most vulnerable to the Phony economic bid weighting (Ballesteros-Pérez et al. 2015b).

\section{PHONY ECONOMIC BID WEIGHTING}

Phony economic bid weighting occurs when the stated value of the economic bid versus the technical proposal does not match with reality. This phenomenon is unavoidable for ESF without SP, but it is also possible (and indeed common) with ESF with one or more SP when they are carelessly designed. Essentially, phony economic bid weightings occur in two occasions:

- When the ESF gives away a proportion of the score, no matter how high or low the bid is, that is, when all bidders earn a percentage of the economic score by default.

- When either the highest scores or the lowest scores are not usually populated by any bid, that is, when most of the bids just concentrate in a relatively narrow range of bid values, causing that all of them have very close scores too.

The general expression for calculating the 'true' economic bid weighting when the weight of the technical bid is complementary to the economic bid $\left(W_{t}=1-W_{e}\right)$ is:

$$
W_{e}^{*}=\frac{W_{e}(1-Q)}{\left(1-W_{e}\right)+W_{e}(1-Q)}=\frac{(1-Q) W_{e}}{1-Q W_{e}}
$$

The meaning of Eq. (2) variables can be found below and a representation in Figure 2.

$W_{e}:$ is the original (phony) Economic Bid Weighting (in /1 values) stated in the tender specs.

$W_{e} *$ : is the true Economic Bid Weighting (in /1 values) with $W_{e}^{*} \leq W_{e}$ always.

$Q$ : is the Fraction of the Economic Score either rarely or almost always achievable (in / 1 values).

$W_{t}$ : is the original Technical Bid Weighting (in / 1 values) stated in the tender specs.

$W_{t}^{*}$ : is the true Technical Bid Weighting (in /1 values) with $W_{t}^{*}=1-W_{e}^{*}$. 


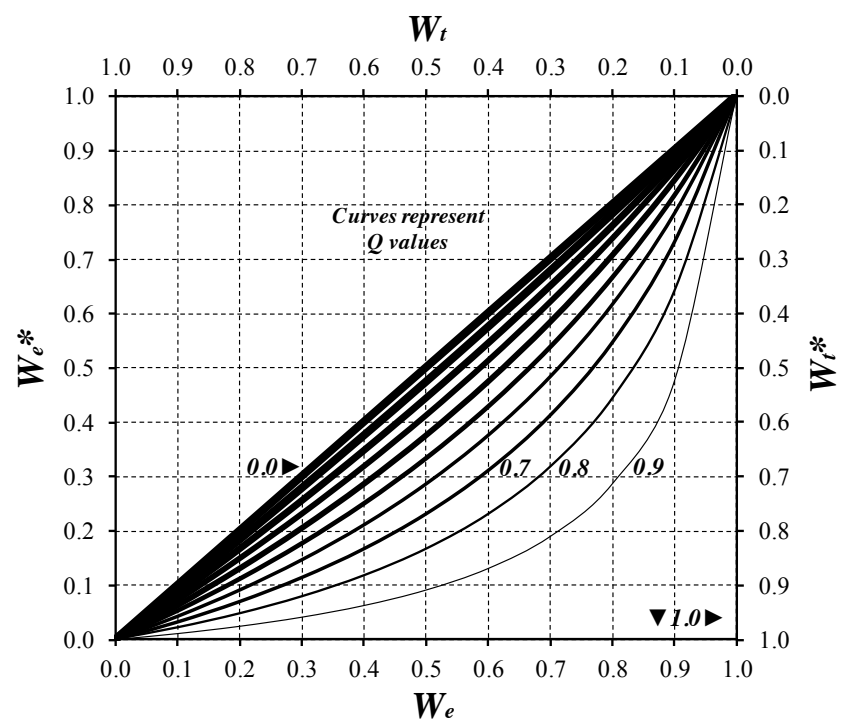

Figure 2. Calculation of the True economic and technical bid weightings ( $\mathrm{Y}$ axes) as a function of the initial Phony economic and technical bid weightings ( $\mathrm{X}$ axes).

This phenomenon acquires more relevance when the phony weights are used intentionally to force the award to a specific bidder. In these cases, bidders' scores differ very little in many transcendent criteria (because they have phony weights), and the award relies on big score difference (because the true weightings are high for that criterion) in an apparently irrelevant criterion, but where a specific bidder has some competitive advantage.

\section{COMPETITIVE IMPLICATIONS OF SPS IMPLEMENTATION}

Despite the use of a specific SP does not have, a priori, advantage over the rest of SPs, it is known that there are some implications concerning how bidders will react when competing with that ESF. Particularly, Table 1 summarizes the relationships between the SPs chosen and the consequences measured with their variation over time in subsequent auctions.

Table 1. Effects of using some SPs over the auction results.

\begin{tabular}{|c|c|c|c|c|}
\hline SP used by the ESF & $\begin{array}{c}\text { Lowest bid } \\
\left(b_{\min }\right)\end{array}$ & $\begin{array}{l}\text { Mean bid } \\
\left(b_{m}\right)\end{array}$ & $\begin{array}{l}\text { Highest bid } \\
\left(b_{\max }\right)\end{array}$ & $\begin{array}{c}\text { Bid st. dev. } \\
(s)\end{array}$ \\
\hline Lowest bid $\left(b_{\min }\right)$ & $\downarrow \downarrow$ & $\downarrow$ & $\approx$ & $\downarrow$ \\
\hline Mean bid $\left(b_{m}\right)$ & $\uparrow$ & $\approx$ & $\downarrow$ & $\uparrow$ \\
\hline Highest bid $\left(b_{\max }\right)$ & $\approx$ & $\downarrow$ & $\downarrow$ & $\uparrow$ \\
\hline Bid st. deviation ( $s$ ) (for ALBC) & $\uparrow \uparrow / \uparrow$ & $\uparrow$ & $\approx$ & $\uparrow$ \\
\hline
\end{tabular}

Therefore, the election of an SP is a vital aspect in the design of the ESF, given that each SP tends to promote different bidding strategies among the bidders. Further qualitative and quantitative justification of the previous table can be found in Ballesteros-Perez (2015b). 


\section{CONCLUSIONS}

In this paper we have analyzed how different aspects of the ESF condition bidders' bidding behavior and bid dispersion. Particularly, aspects related to the weights of the economic and technical criteria have been described and a phenomenon that affects them (phony economic bid weighting) formulated mathematically. Also, the variables that ESF implement: the Scoring Parameters have been classified and the effects of using one, two or even none SP qualitatively classified. Further research is needed in this topic in the near future nonetheless, which looks quite relevant to optimize how public money is spent.

\section{References}

Abudayyeh, O., Zidan, S.J., Yehia, S., and Randolph, D., Hybrid Prequalification-Based, Innovative Contracting Model Using AHP, Journal of Management in Engineering, ASCE, 23:2(8), 88-96, 2007.

Ballesteros-Pérez, P., González-Cruz, M. C. and Pastor-Ferrando, J. P., Analysis of construction projects by means of value curves. International Journal of Project Management, Elsevier, 28(7), 719-731, 2010.

Ballesteros-Pérez, P., del Campo-Hitschfeld, M. L., Mora-Melià, D. and Domínguez, D., Modeling bidding competitiveness and position performance in multi-attribute construction auctions. Operations Research Perspectives, 2, 24-35. 2015a.

Ballesteros-Pérez, P., Skitmore, M., Pellicer, E., and González-Cruz, M. C., Scoring rules and abnormally low bids criteria in construction tenders: a taxonomic review, Construction Management and Economics, Taylor and Francis, 33(4), 259-278, 2015 b.

Ballesteros-Pérez, P., Skitmore, M., Das, R. and del Campo-Hitschfeld, M. L., Quick abnormal-biddetection method for construction contract auctions. Journal of Construction Engineering and Management, ASCE, 141(7), 04015010, 2015c.

Ballesteros-Pérez, P.; Skitmore, M.; Pellicer, E., and Zhang, X., Scoring Rules and Competitive Behavior in Best-Value Construction Auctions, Journal of Construction Engineering and Management, ASCE, 142(9), 04016035, 2016.

Bergman, M.A., and Lundberg, S., Tender evaluation and supplier selection methods in public procurement, Journal of Purchasing \& Supply Management, Elsevier, 19(2), 73-83, 2013.

Constantino, N., Falagario, M., Pietroforte, R., and Sciancalepore, F., A model for predicting the bid distribution in public tenders, in 4th International Public Procurement Conference. Part 4. Economics of Procurement, 2010.

Drew, D., Tang S., and Lo, S.O., Developing a tendering strategy in two-envelope fee tendering based on technical score-fee variability, Construction Management and Economics, Taylor and Francis, 20(1), 67-81, 2002.

El Wardani, M.A., Messner, J.I., and Horman M.J., Comparing procurement methods for design-build projects. Journal of Construction Engineering and Management, ASCE, 132:3(230), 230-238, 2006.

Hong, C., Contractor Performance Prediction Model for the United Kingdom Construction Contractor: Study of Logistic Regression Approach. Journal of Construction Engineering and Management, ASCE, 130:5(691), 691-698, 2004.

Molenaar, K.R., and Johnson D.E., Engineering the procurement phase to achieve best value. Leadership and Management in Engineering, ASCE, 3:3(137), 137-141, 2003.

Pastor-Ferrando, J.P., Aragonés-Beltrán, P., Hospitaler-Pérez, A., and García-Melón, M., An ANP and AHP based approach for weighting criteria in public works bidding. Journal of the Operational Research Society, Springer, 61(6), 905-916, 2010.

Perng, Y., Yi-Kai, J., and Chien, S., Exploring the Bidding Situation for Economically Most Advantageous Tender Projects Using a Bidding Game. Journal of Construction Engineering and Management, ASCE, 132(10), 1037-1042, 2006.

Skitmore, R.M., Predicting the probability of winning sealed bid auctions: A comparison of models. Journal of the Operational Research, Springer, 53(1), 47-56, 2002.

Tsai, H., Wang, L., and Lin, L., A study on improving the ranking procedure for determining the most advantageous tender. Construction Management and Economics, Taylor and F., 25(5), 545-554, 2007. 